\title{
Composição Corporal e Requisitos Energéticos e Protéicos de Bovinos Nelore, Não-Castrados, Alimentados com Rações Contendo Diferentes Níveis de Concentrado e Proteína ${ }^{1}$
}

\section{Fabiano Ferreira da Silva ${ }^{2}$, Sebastião de Campos Valadares Filho ${ }^{3}$, Luís Carlos Vinhas Ítavo ${ }^{4}$, Cristina Mattos Veloso ${ }^{2}$, Rilene Ferreira Diniz Valadares ${ }^{5}$, Paulo Roberto Cecon ${ }^{6}$, Pedro Veiga Rodrigues Paulino7, Eduardo Bevitori Kling de Moraes ${ }^{7}$}

\begin{abstract}
RESUMO - Foram utilizados 40 novilhos Nelore inteiros, com peso vivo médio inicial de $240 \mathrm{~kg}$, sendo quatro novilhos de referência, quatro alimentados para mantença e o restante distribuído em oito tratamentos, com quatro diferentes níveis de concentrado nas dietas $(20 ; 40 ; 60$ e $80 \%)$ e dois níveis de proteína bruta (PB) (15 e 18\%). Os conteúdos de proteína, gordura e energia retidos no corpo foram estimados por meio de equações de regressão do logaritmo do conteúdo corporal de proteína, gordura ou energia, em função do logaritmo do PCVZ. Derivando-se as equações de predição do conteúdo corporal de proteína, gordura, ou energia, em função do logaritmo do peso de corpo vazio (PCVZ), foram obtidas as exigências líquidas de proteína e energia, para ganho de $1 \mathrm{~kg}$ de PCVZ, a partir de equação $\mathrm{Y}^{\prime}=$ b. $10^{\mathrm{a}}$. $\mathrm{X}^{\mathrm{b}-1}$, sendo a e b a intercepta e o coeficiente de regressão, respectivamente, das equações de predição dos conteúdos corporais de proteína ou energia. As exigências líquidas de energia para mantença (ELm) foram estimadas como o anti-log da intercepta da equação obtida pela regressão linear entre o logaritmo da produção de calor (PC) e o consumo de energia metabolizável (CEM). As exigências de energia líquida para ganho de peso de zebuínos não-castrados podem ser obtidas pela equação: $\mathrm{ELg}=0,0413 \times \mathrm{PCVZ}^{0,75} \times$ ganho diário de PCVZ ${ }^{0,978}$. A ELm, obtida neste experimento, foi de $83,70 \mathrm{kcal} / \mathrm{PCVZ}^{0,75}$, para animais não-castrados pertencentes à raça Nelore. Foi obtida a seguinte equação para estimativa da proteína retida (PR), em função do GMD e da energia retida (ER): PR = - 39,0169 + 200,638 ganho de peso vivo em jejum (GPVJ) $+0,4166$ ER. A exigência líquida de proteína de Nelore, não-castrado diminuiu com o aumento do peso vivo, sendo de 183,22 e $173,72 \mathrm{~g} / \mathrm{kg}$ GPCVZ para animais de 200 e $400 \mathrm{~kg}$ de peso vivo, respectivamente.
\end{abstract}

Palavras-chave: energia, exigências, Nelore, proteína

\section{Body Composition and Energy and Protein Requirements of Nellore Bulls Fed Diets with Different Concentrate and Protein Levels}

\begin{abstract}
Forty Nellore bulls, with average initial live weight (LW) of $240 \mathrm{~kg}$, were used. Four reference bulls and four bulls fed for maintenance were used, and the remaining was assigned to eight treatments, with four different concentrate levels in the diets $(20,40,60$ and $80 \%)$ and two (15 and 18\%) levels of crude protein (CP). The protein, fat and energy contents retained in the body were estimated by regression equations of the logarithm of protein, fat or energy body content, as a function of the logarithm of empty body weight (EBW). By deriving the prediction equations of body content of protein, fat, or energy, as a function of the EBW logarithm, the net requirements of protein and energy, for gains of $1 \mathrm{~kg} E B W$, were determined. The deriving equation was $\mathrm{Y}=\mathrm{b} \cdot 10^{\mathrm{a}}$. $\mathrm{X}^{\mathrm{b}-1}$, being a and $\mathrm{b}$ intercept and regression coefficient, respectively, of the prediction equations of protein or energy body contents. Net energy requirement for maintenance (NEm) was estimated as the intercept anti-log of the equation obtained by linear regression among the logarithm of heat production and the metabolizable energy intake. The net energy requirement for weight gain of zebu bulls can be obtained by the equation: $\mathrm{NEg}=0.0413 \mathrm{x} \mathrm{EBW}^{0.75} \mathrm{x}$ gain of EBW ${ }^{0.978}$. The NEm for these animals was $83.70 \mathrm{kcal} / \mathrm{EBW}^{0.75}$. The following equation was obtained to estimate the retained protein (RP), as a function of EBW gain and retained energy $(\mathrm{RE}): \mathrm{RP}=-39.0169+200.638$ gain of $\mathrm{EBW}+0.4166 \mathrm{RE}$. The net protein requirement of Nellore bulls decreased as the LW increased, being 183.22 and $173.72 \mathrm{~g} / \mathrm{kg}$ of EBW gain for animals with 200 and $400 \mathrm{~kg}$ of LW, respectively.
\end{abstract}

Key Words: energy, Nellore, protein, requirements

\footnotetext{
1 Parte da tese de Doutorado em Zootecnia apresentada pelo primeiro autor à UFV. Financiada pela FAPEMIG.

2 Professor do curso de Zootecnia - UESB - Pç. Primavera, 40 - Itapetinga, BA - 45700-000. E.mail: ffsilva@uesb.br; cmveloso@uesb.br

3 Professor do Departamento de Zootecnia - UFV - Viçosa, MG. E.mail: svcfilho@ufv.br

4 Professor da Universidade Católica Dom Bosco - Campo Grande, MS. E.mail: itavo@ucdb.br

5 Professor do Departamento de Medicina Veterinária - UFV - Viçosa, MG. E.mail: svcfilho@ufv.br

6 Professor do Departamento de Informática - UFV - Viçosa, MG.

${ }^{7}$ Mestrando em Zootecnia/UFV - Viçosa, MG. E.mail: eg35439@correio.ufv.br; edukling@bol.com.br
} 


\section{Introdução}

A melhoria no desempenho produtivo do rebanho nacional exige o aprofundamento de estudos que possibilitem estabelecer as exigências nutricionais de bovinos em condições brasileiras. Devem-se considerar a peculiaridade dos animais e o tipo de alimento empregado, visando à elaboração de rações eficientes e de custo mínimo.

$\mathrm{Na}$ formulação de rações, ainda são utilizadas tabelas de exigências nutricionais determinadas em outros países, nos quais os resultados de pesquisa revelam diferenças nos requisitos entre raças e categorias de bovinos, estado fisiológico, regiões e, até mesmo, estações do ano.

O processo de crescimento é o resultado líquido de síntese e degradação, e não somente simples acréscimos de água, proteína, gordura e minerais no corpo. Existe um paralelismo entre os modelos de crescimento dos componentes químicos (água, proteína, cinzas e gordura) e físicos (músculos, ossos e tecidos adiposos) do corpo do animal. O crescimento de músculo e gordura parece variar largamente entre grupos de animais, ao passo que o crescimento de ossos parece ser semelhante, independentemente do tipo de bovino. Variações na distribuição destes componentes no corpo do animal podem conduzir a diferenças nos requisitos nutricionais entre raças e cruzamentos (Robelin \& Geay, 1984). As diferenças na composição do ganho de peso são responsáveis pela maior exigência de energia para ganho em animais em um estádio mais avançado de maturidade fisiológica, pela maior exigência de animais precoces em relação aos tardios a um mesmo peso vivo e pela maior exigência das fêmeas em relação aos machos inteiros (Lana, 1991).

Em 1963, Lofgreen e Garrett introduziram o sistema de energia líquida para crescimento e engorda de gado de corte (Lofgreen \& Garrett, 1968). O sistema separa os requisitos de energia líquida em requisitos de energia para mantença e ganho de peso (crescimento e engorda). A soma das necessidades de mantença e ganho representa as exigências líquidas de energia dos animais. Conhecendo-se as exigências líquidas e levando-se em consideração os fatores de eficiência de utilização da energia alimentar para mantença e ganho, obtêm-se as exigências de energia metabolizável. As exigências de energia para mantença variam com o sexo, a raça, a idade, a composição corporal e o nível nutricional do animal
(Silva \& Leão, 1979; Solis et al., 1988). Variações nas exigências de mantença podem, também, ser explicadas, em parte, por variações nas proporções de vários tecidos ou órgãos do corpo. Alguns estudos sugerem que a proteína do corpo, especialmente em órgãos viscerais, é metabolicamente muito mais ativa que o tecido adiposo e pode responder por diferenças em requisitos de mantença, por unidade de $\mathrm{PV}^{0,75}$, entre diferentes tipos biológicos e estádios de desenvolvimento. A reciclagem protéica e o transporte de íons através das células representam mais de $50 \%$ do gasto total de energia para mantença (Baldwin et al., 1980). Garrett (1980) observou que diferenças na intensidade de reciclagem protéica podem ser responsáveis pelos maiores requisitos de energia para mantença, para determinado peso vivo, em raças bovinas que atingem a maturidade com pesos mais elevados, em machos inteiros em relação a castrados e destes em relação às fêmeas.

Os requisitos de energia líquida para mantença para o gado de corte foram estimados em $77 \mathrm{kcal}$ por unidade de tamanho metabólico (Garrett, 1980; NRC, 1996). Segundo o NRC (1996), as exigências de energia para mantença de raças zebuínas são menores que as encontradas quando se utilizam as equações de Lofgreen \& Garrett (1968). Para o Cornell Net Carbohydrate Protein System - CNCPS (Fox et a1., 1992), os animais zebuínos apresentam exigências de $89 \%$ em relação ao valor básico de $77 \mathrm{kcal} / \mathrm{kg}^{0,75}$, usado pelo NRC (1996).

As diferenças nas exigências de energia líquida para mantença (ELm) entre grupos genéticos podem ser, em parte, explicadas por diferenças no tamanho de seus órgãos internos, que são maiores nos taurinos do que nos zebuínos. Jorge (1993) verificou menor tamanho de órgãos internos de animais Nelore em relação a animais mestiços europeu-zebu. Somando-se a isso, os zebuínos apresentaram menores depósitos de gordura interna (Peron et al., 1993), que são metabolicamente mais ativos e têm influência nas exigências de mantença (Thompson et al., 1983).

Salvador (1980) obteve, para novilhos azebuados, ELm de $56 \mathrm{kcal} / \mathrm{kg}^{0,75} /$ dia. Trabalhando com animais da raça Nelore, Gonçalves (1988) e Freitas (1995) encontraram valores de 59,8 e $50,2 \mathrm{kcal} / \mathrm{kg}^{0,75} / \mathrm{dia}$, respectivamente. Para animais de quatro raças zebuínas (Gir, Tabapuã, Guzerá e Nelore), Paulino et al. (1999a) obtiveram valor médio de ELm de $60,4 \mathrm{kcal} / \mathrm{kg}^{0,75} / \mathrm{dia}$. Por outro lado, Boin (1995) encontrou valor de $69,8 \mathrm{kcal} / \mathrm{kg}$ Peso de Corpo Vazio - PCVZ 
Os requisitos de energia líquida para crescimento (ELg) são estimados como a quantidade de energia depositada como matéria orgânica não-gordurosa (a maior parte, proteína) mais aquela depositada como gordura (NRC, 1996).

O NRC (1984) ressalta valores variando de 1,2 a 8,0 Mcal $/ \mathrm{kg}$ de ganho e o ARC (1980) sugere concentração de energia no ganho de peso variando de $8,6 \mathrm{MJ} / \mathrm{kg}$, para animais de $235 \mathrm{~kg}$ de peso de corpo vazio, a $16 \mathrm{MJ} / \mathrm{kg}$, para bovinos com $550 \mathrm{~kg}$ de peso do corpo vazio.

Fontes (1995), em análise conjunta de vários experimentos, encontrou diferenças na composição corporal e no ganho de energia entre animais castrados e não-castrados; portanto, as exigências líquidas para ganho foram diferentes, de forma que os requisitos nutricionais de bovinos de corte deverão ser estabelecidos separadamente para animais castrados e não-castrados. Os requisitos líquidos de energia estimados para Nelore de $400 \mathrm{~kg}$ de PCVZ foram 4,75 e 9,02 Mcal/kg de GPCVZ para não-castrado e castrado, respectivamente (Fontes, 1995). Boin (1995) encontrou requisitos de 3,5 e 4,4 Mcal/dia para animais Nelores não-castrados e de 5,0 e 6,2 Mcal/dia para Nelores castrados pesando 300 e $400 \mathrm{~kg}$ de PCVZ, respectivamente.

As exigências de proteína para mantença representam as perdas metabólicas fecais, urinárias e descamações. Medir as perdas metabólicas é muito difícil, principalmente as fecais, pois não se dispõe de técnicas acuradas para a separação das perdas microbianas (células completas ou paredes celulares), nas fezes, das verdadeiras perdas metabólicas fecais.

O Institut National de la Recherche Agronomique (INRA, 1988), utilizando resultados de estudos de balanço de $\mathrm{N}$, que incluíam descamações e perdas metabólicas, urinárias e fecais, determinou que a exigência de proteína metabolizável para mantença foi de $3,25 \mathrm{~g} / \mathrm{kg} \mathrm{PCVZ}^{0,75} / \mathrm{dia}$. Smuts (1935) calculou esta mesma exigência em $3,52 \mathrm{~g} / \mathrm{kg} \mathrm{PV}^{0,75} / \mathrm{dia}$ utilizando o balanço de N. Wilkerson et al. (1993) estimaram as exigências de proteína metabolizável para mantença em $3,8 \mathrm{~g} / \mathrm{kg} \mathrm{PV}^{0,75} /$ dia, utilizando o crescimento como critério, e não o balanço de N. Esta foi a razão por que o NRC (1996) adotou o valor encontrado por Wilkerson et al. (1993).

Os requisitos líquidos de proteína para bovinos em crescimento e terminação são função do conteúdo de matéria seca livre de gordura no peso ganho e variam com a raça, a classe sexual e a taxa de ganho de peso. São maiores para animais não-castrados do que para castrados e, dentro de um mesmo sexo, são maiores para animais de maturidade tardia do que para os de maturidade precoce (Geay, 1984), provavelmente devido ao maior potencial para crescimento muscular de animais não-castrados e/ou de maturidade tardia.

Fontes (1995), analisando, conjuntamente, vários experimentos, apresentou exigências líquidas de proteína para ganho de $1 \mathrm{~kg}$ de PCVZ, de animais Nelore e mestiços, de 0,189 e 0,174 kg para animais não-castrados com PCVZ de 200 e $400 \mathrm{~kg}$, respectivamente.

Os requisitos de proteína metabolizável (PM) são obtidos pela relação entre os requisitos líquidos e a eficiência de utilização da proteína. O AFRC (1993) preconizou a eficiência de utilização da proteína metabolizável para ganho de peso como 59\%. O NRC (1996) utiliza uma equação para estimativa da eficiência de utilização da PM para todos as raças bovinas com PCVZ menor que $300 \mathrm{~kg}$ ( $\mathrm{PM}=$ exigências líquidas/(83,4 - (0,114 x xPCVZ))) e, para animais com PCVZ maior que $300 \mathrm{~kg}$, preconizou eficiência de 49,2\%.

Os objetivos do presente trabalho foram determinar a composição corporal e as exigências de energia e proteína de animais Nelore não-castrados, alimentados com dietas contendo diferentes níveis de concentrado e proteína.

\section{Material e Métodos}

O experimento foi realizado no Departamento de Zootecnia da Universidade Federal de Viçosa, em Viçosa-MG. Foram utilizados 40 novilhos Nelore inteiros, com peso vivo médio inicial de $240 \mathrm{~kg}$. Quatro novilhos foram abatidos após o período de adaptação de 30 dias (grupo referência), servindo de referência para a composição corporal inicial. Quatro novilhos foram alimentados com uma dieta contendo $60 \%$ de concentrado e $15 \%$ de $\mathrm{PB}$, em consumo restrito de $1,2 \%$ do peso vivo (grupo mantença), para atender os requisitos energéticos de mantença, calculados segundo o NRC (1996). Os 32 animais restantes foram pesados e distribuídos em oito tratamentos, com quatro níveis de concentrado nas dietas $(20$; 40, 60 e $80 \%$ ) e dois níveis de PB (15 e 18\%), na base da MS, em esquema fatorial 4 x 2 (níveis de concentrado $\mathrm{x}$ níveis de proteína), no delineamento inteiramente casualizado com quatro repetições na fase de recria e duas repetições na fase de engorda. A fase 
de recria foi avaliada dos 240 aos $360 \mathrm{~kg}$ de peso vivo e a fase de engorda, dos 360 aos $450 \mathrm{~kg}$ de peso vivo. O volumoso foi composto de feno de gramínea Cynodon dactylon $(L)$ Pears. cultivar Tifton 85. As rações foram formuladas de acordo com o NRC (1996) e para conter próximo de $32 \%$ de compostos nitrogenados não-protéicos. A proporção dos ingredientes e a composição bromatológica das dietas e do feno encontram-se nas Tabelas 1 e 2.

Os alimentos foram fornecidos à vontade, uma vez ao dia, e ajustados de forma a manter sobras de 5 a $10 \%$ do fornecido, com água permanentemente à disposição dos animais. Foi realizada uma pesagem dos animais no início do experimento e, periodicamente, a cada 28 dias. À medida que um animal se aproximava do peso de abate preestabelecido, 360 ou $450 \mathrm{~kg}$ (recria e engorda, respectivamente), era pesado a intervalos menores ( 7 dias). Antes do abate, os animais foram submetidos a jejum de 16 horas. Após o abate, o trato gastrintestinal foi pesado, esvaziado e lavado e seu peso, após escorrer a água, foi somado aos órgãos e demais partes do corpo (carcaça, cabeça, couro, cauda, pés e sangue) para determinação do PCVZ. A relação obtida entre o PCVZ e o peso vivo (PV) dos animais referência foi utilizada para a estimativa do PCVZ inicial dos animais que permaneceram no experimento. Dentro de cada tratamento, aleatoriamente foi sorteado um ani- mal, do qual foram retirados a cabeça e um membro anterior e outro posterior, para, em seguida, proceder-se à separação física de músculos, gordura, ossos e couro e posterior pesagem. A relação dos constituintes físicos na cabeça e nas patas destes animais foi utilizada para estimar o peso destes constituintes dos outros animais dos respectivos tratamentos.

As amostras de sangue foram coletadas imediatamente após o abate, acondicionadas em recipiente de vidro e levadas à estufa de ventilação forçada, a $55-60^{\circ} \mathrm{C}$, durante 48 a 72 horas, para determinação do teor de matéria seca (MS), sendo, a seguir, processadas em moinho de bola e acondicionadas em recipientes apropriados, para posteriores análises de nitrogênio total e extrato etéreo, conforme Silva (1990), sendo que o teor de proteína foi obtido pelo produto entre o teor de nitrogênio total e o fator 6,25 .

A carcaça de cada animal foi dividida em duas meia-carcaças, as quais foram pesadas e, em seguida, resfriadas em câmara fria a $-5^{\circ} \mathrm{C}$, durante 18 horas. Decorrido este tempo, as meia-carcaças foram retiradas da câmara fria, e foi coletada e pesada uma amostra da meia-carcaça esquerda, correspondente à seção entre a $9^{\mathrm{a}}$ e $11^{\mathrm{a}}$ costelas (seção Hankins e Howe - HH), para posteriores dissecação e predição das proporções de músculos, ossos e tecido adiposo na carcaça, segundo equações preconizadas por Hankins \& Howe (1946):

Tabela 1 - Proporção dos ingredientes nos concentrados, na base da matéria natural

Table 1 - Ingredients proportion in the concentrate, as fed basis

\begin{tabular}{|c|c|c|c|c|c|c|c|c|}
\hline \multirow{2}{*}{$\begin{array}{l}\text { Nível de concentrado }(\%) \\
\text { Concentratelevel } \\
\text { Teor de PB } \\
\text { CP content }\end{array}$} & \multicolumn{2}{|c|}{20} & \multicolumn{2}{|c|}{40} & \multicolumn{2}{|c|}{60} & \multicolumn{2}{|c|}{80} \\
\hline & 15 & 18 & 15 & 18 & 15 & 18 & 15 & 18 \\
\hline $\begin{array}{l}\text { Fubá de milho, \% } \\
\text { Corn }\end{array}$ & 88,72 & 59,74 & 91,96 & 77,10 & 93,05 & 83,20 & 95,37 & 86,16 \\
\hline $\begin{array}{l}\text { Farelo de soja, } \% \\
\text { Soybean meal }\end{array}$ & 4,75 & 32,44 & 4,38 & 18,35 & 4,03 & 13,50 & 1,76 & 11,01 \\
\hline $\begin{array}{l}\text { Uréia, \% } \\
\text { Urea }\end{array}$ & 2,93 & 4,65 & 1,58 & 2,43 & 1,16 & 1,70 & 1,25 & 1,35 \\
\hline $\begin{array}{l}\text { Calcáreo calcítico, } \% \\
\text { Calcitic limestone }\end{array}$ & 0,045 & 0,02 & 0,54 & 0,79 & 0,88 & 0,87 & 1,04 & 1,04 \\
\hline $\begin{array}{l}\text { Fosfato bicálcico, } \% \\
\text { Dicalcium phosphate }\end{array}$ & 2,78 & 2,42 & 1,12 & 0,94 & 0,57 & 0,45 & 0,33 & 0,20 \\
\hline $\begin{array}{l}\text { Sal comum, } \% \\
\text { Salt }\end{array}$ & 0,70 & 0,65 & 0,38 & 0,36 & 0,28 & 0,26 & 0,23 & 0,21 \\
\hline $\begin{array}{l}\text { Premix mineral, } \mathrm{g} / 100 \mathrm{~kg}^{1} \\
\text { Mineral premix }\end{array}$ & 84,04 & 84,04 & 42,02 & 42,02 & 28,00 & 28,00 & 21,00 & 21,00 \\
\hline
\end{tabular}

${ }^{1}$ Composição: Sulfato de zinco, 80,00\%; Sulfato de cobre, 19,00\%; lodato de potássio, 0,50\%; Sulfato de cobalto, 0,25\%; Selenito de sódio, 0,25\%. Composition: Zinc sulfate, $80.00 \%$; Copper sulfate, $19.00 \%$; Potassium iodide, 0.50\%; Cobalt sulfate, $0.25 \%$; Sodium selenite, $0.25 \%$. 
Tabela 2 - Teores médios de matéria seca (MS), proteína bruta (PB), extrato etéreo (EE), fibra em detergente neutro (FDN) e nutrientes digestíveis totais (NDT) das dietas experimentais e do feno

Table 2 - Average contents of dry matter (DM), crude protein (CP), ether extract (EE), neutral detergent fiver (NDF) and total digestible nutrients (TDN) of the experimental diets and hay

\begin{tabular}{|c|c|c|c|c|c|c|c|c|c|}
\hline \multirow{2}{*}{$\begin{array}{l}\text { Nível de concentrado }(\%) \\
\text { Concentrate level } \\
\text { Teor de PB } \\
\text { CP content }\end{array}$} & \multicolumn{2}{|c|}{20} & \multicolumn{2}{|c|}{40} & \multicolumn{2}{|c|}{60} & \multicolumn{2}{|c|}{80} & \multirow[b]{2}{*}{$\begin{array}{l}\text { Feno } \\
\text { Hay }\end{array}$} \\
\hline & 15 & 18 & 15 & 18 & 15 & 18 & 15 & 18 & \\
\hline$\overline{\mathrm{MS}}(D M), \%$ & 88,21 & 88,28 & 88,05 & 88,09 & 87,79 & 87,92 & 87,58 & 87,67 & $\overline{88,55}$ \\
\hline $\mathrm{PB}(C P)^{1}$ & 15,67 & 18,85 & 15,10 & 17,63 & 15,11 & 18,26 & 14,52 & 17,11 & 14,09 \\
\hline $\mathrm{EE}^{1}$ & 2,30 & 2,05 & 3,03 & 1,76 & 2,46 & 2,13 & 1,95 & 1,93 & 1,93 \\
\hline FDN $(N D F)^{1,2}$ & 62,37 & 60,60 & 48,62 & 46,46 & 37,90 & 34,62 & 25,94 & 19,65 & 74,47 \\
\hline $\operatorname{NDT}(T D N)^{1,3}$ & 73,80 & 73,16 & 77,73 & 79,33 & 79,61 & 81,46 & 81,94 & 78,39 & 61,68 \\
\hline
\end{tabular}

$1 \%$ na matéria seca (\% in dry matter).

${ }^{2}$ FDN corrigida para cinzas e proteína (NDF corrected for ash and protein).

3 Obtido em ensaio de digestibilidade com os mesmos animais (Ítavo, 2001) (Obtained from the digestibility experiment with the same animals).

Proporção de músculo: $\quad \mathrm{Y}=16,08+0,80 \mathrm{X}$ Proporção de tecido adiposo: $\mathrm{Y}=3,54+0,80 \mathrm{X}$ Proporção de ossos: $\quad \mathrm{Y}=5,52+0,57 \mathrm{X}$ em que: $\mathrm{X}=$ porcentagem dos componentes na seção $\mathrm{HH}$.

As amostras de rúmen, retículo, omaso, abomaso, intestino delgado, intestino grosso, gordura interna, mesentério e aparas (esôfago, traquéia e aparelho reprodutor) foram agrupadas de forma proporcional e constituíram uma amostra composta de vísceras, enquanto as de fígado, coração, rins, pulmões, língua, baço e carne industrial, agrupadas também de forma proporcional, compuseram a amostra de órgãos.

Excetuando-se as amostras de sangue, amostras de $200 \mathrm{~g}$ de compostas de órgãos e de vísceras, músculos e gordura, após moídas, e amostras de $100 \mathrm{~g}$ de couro, ossos e cauda, após seccionadas, foram acondicionadas em vidros com capacidade de $500 \mathrm{~mL}$ e levadas ao liofilizador, por um período de 24 a 72 horas, dependendo da amostra, para determinação da matéria seca gordurosa (MSG). As amostras de ossos permaneceram 24 horas; as de órgãos, músculo, couro e rabo, 48 horas; e as de vísceras e gordura, 72 horas, em média, no liofilizador.

Posteriormente, procedeu-se ao desengorduramento das referidas amostras, com lavagens sucessivas com éter de petróleo, obtendo-se a matéria seca prédesengordurada (MSPD). Em seguida, as amostras foram processadas em moinho de bola, para posteriores determinações de nitrogênio total e extrato etéreo, conforme metodologias descritas por Silva (1990). A gordura removida no pré-desengorduramento foi calculada como a diferença entre a MSG e a MSPD e adicionada aos resultados obtidos para o extrato etéreo residual na MSPD, para determinação do teor total de gordura. A partir do conhecimento dos teores de proteína e extrato etéreo na MSPD e do peso da amostra submetida ao pré-desengorduramento, determinaram-se os respectivos teores na matéria natural.

Os conteúdos corporais de gordura, proteína e água foram determinados em função de suas concentrações percentuais nos órgãos, vísceras, couro, sangue, cauda, cabeça, pés e constituintes separados (gordura, músculos e ossos) da seção $\mathrm{HH}$; estes últimos representaram a composição física da carcaça e, quanto à composição química, estimaram apenas o teor de proteína na carcaça. Foram construídas duas equações para estimar a porcentagem de lipídios e de água na carcaça, a partir da porcentagem de lipídios na seção HH (Silva, 2001):

$\%$ lipídios na carcaça $=1,5113+0,6832 * X, r^{2}=0,752$ $\%$ água na carcaça $=71,8989-0,6006 * X, r^{2}=0,864$

em que: $\mathrm{X}=\%$ de lipídio na seção $\mathrm{HH}$.

A porcentagem de proteína da carcaça foi calculada pela multiplicação da composição física da carcaça (estimada pela seção $\mathrm{HH}$ ) pela composição química dos respectivos constituintes da seção $\mathrm{HH}$ (músculo, ossos e gordura).

A determinação da energia corporal foi obtida a partir das quantidades corporais de proteína e gordura e seus respectivos equivalentes calóricos, conforme a equação preconizada pelo ARC (1980):

$$
\mathrm{CE}=5,6405 \mathrm{X}+9,3929 \mathrm{Y}
$$

em que: $\mathrm{CE}=$ conteúdo energético (Mcal); $\mathrm{X}=$ proteína corporal $(\mathrm{kg}) ; \mathrm{Y}=$ gordura corporal $(\mathrm{kg})$.

Os conteúdos de gordura, proteína e energia retidos no corpo dos animais de cada tratamento e para todos os tratamentos em conjunto foram estimados por meio de equações de regressão do logaritmo 
do conteúdo corporal de proteína, gordura ou energia, em função do logaritmo do PCVZ, segundo o ARC (1980), conforme o seguinte modelo:

$$
\mathrm{Y}=\mathrm{a}+\mathrm{bX}+\mathrm{e}
$$

em que: $\mathrm{Y}=$ logaritmo do conteúdo total de proteína $(\mathrm{kg})$, gordura $(\mathrm{kg})$ ou energia (Mcal) retido no corpo vazio; $a=$ constante; $b=$ coeficiente de regressão do logaritmo do conteúdo de proteína, gordura, ou energia, em função do logaritmo do PCVZ; $\mathrm{X}=$ logaritmo do PCVZ; e = erro aleatório.

Para cada tratamento, as equações foram construídas adicionando-se os valores relativos aos animais referência.

Derivando-se as equações de predição do conteúdo corporal de proteína, gordura, ou energia, em função do logaritmo do PCVZ, foram obtidas as equações de predição dos conteúdos de proteína, gordura, ou energia, por kg de ganho de PCVZ. As exigências líquidas de proteína e energia, para ganho de $1 \mathrm{~kg}$ de PCVZ, corresponderam aos respectivos conteúdos no ganho de corpo vazio e foram obtidas, juntamente com o conteúdo de gordura no ganho de corpo vazio, a partir de equação do tipo:

$$
\mathrm{Y}^{\prime}=\text { b. } 10^{\mathrm{a}} \cdot \mathrm{X}^{\mathrm{b}-1}
$$

em que: $Y^{\prime}=$ conteúdo de gordura no ganho, ou exigência líquida de proteína ou energia; a e b = intercepto e coeficiente de regressão, respectivamente, das equações de predição dos conteúdos corporais de gordura, proteína ou energia; e

$$
\mathrm{X}=\operatorname{PCVZ}(\mathrm{kg}) \text {. }
$$

Os requisitos de proteína metabolizável para mantença (PMm) e ganho (PMg) e as exigências de proteína bruta foram obtidos segundo o NRC (1996).

Para a conversão do PV em PCVZ, dentro do intervalo de pesos incluído no trabalho, calculou-se a correlação entre o PCVZ dos 32 animais mantidos no experimento e o PV dos mesmos. Para conversão das exigências para ganho de PCVZ em exigências para ganho de $\mathrm{PV}$, utilizou-se o fator obtido a partir dos dados experimentais.

Foi efetuada uma equação de regressão entre a energia retida (ER) e o ganho diário de PCVZ (GDPCVZ), para determinado PCVZ, conforme preconizado pelo NRC (1984 e 1996).

A produção de calor em jejum ou as exigências líquidas de energia para mantença (ELm) foram estimadas como o anti-log do intercepto da equação obtida pela regressão linear entre o logaritmo da produção de calor (PC) e o consumo de energia metabolizável (CEM), segundo Lofgreen e Garrett
(1968). A produção de calor foi calculada pela diferença do consumo total de energia metabolizável pelo total de energia retida no corpo de todos os animais incluindo os alimentados em nível de mantença. $\mathrm{O}$ CEM foi expresso em $\mathrm{kcal} / \mathrm{kg} \mathrm{PCVZ}^{0,75}$.

As determinações de matéria seca (MS), compostos nitrogenados totais, extrato etéreo (EE) e fibra em detergente neutro (FDN) foram feitas conforme técnicas descritas por Silva (1990). Os teores de nutrientes digestíveis totais (NDT) foram obtidos do experimento de Ítavo (2001).

Os resultados foram interpretados estatisticamente por meio de análises de variância e regressão, utilizando-se o Sistema de Análises Estatísticas e Genéticas - SAEG (UFV, 1995). As comparações entre as equações de regressão dos parâmetros avaliados para cada tratamento foram realizadas de acordo com a metodologia recomendada por Regazzi (1996), para testar identidade de modelos.

\section{Resultados e Discussão}

A relação obtida para estimativa do PCVZ, a partir do PV dos animais do presente trabalho foi: $\mathrm{PCVZ}=\mathrm{PV} * 0,8975$, próximo ao valor recomendado pelo NRC (1996), 0,891 e por Véras (2000), 0,884.

A relação entre o GPCVZ e o GPV foi de 0,96. Portanto, nas condições do presente experimento, as exigências para ganho de $1 \mathrm{~kg}$ de PCVZ devem ser multiplicadas pelo fator 0,96 para se obterem as exigências líquidas para ganho de $1 \mathrm{~kg}$ de PV. O NRC (1996) utiliza a relação 0,956 entre o GPCVZ e o GPV.

Em virtude de o PCVZ ser influenciado pelo nível de concentrado (NC) na dieta (Robelin \& Geay, 1984), foi efetuada regressão do PCVZ, em função do PV final, ou de abate, dos animais, e do NC nas rações. A equação obtida foi: $\mathrm{PCVZ}=-12,6424+$ $0,90588 \mathrm{PV}+0,235497 \mathrm{NC}, \mathrm{R}^{2}=0,99$.

Na Tabela 3 são apresentados os parâmetros das equações de regressão do logaritmo dos conteúdos de gordura $(\mathrm{kg})$, proteína $(\mathrm{kg})$ e energia (Mcal) no corpo vazio, em função do logaritmo do PCVZ, obtidos para cada tratamento e para todos os tratamentos em conjunto. O teste de identidade entre os modelos, aplicado às equações de regressão do logaritmo do conteúdo corporal de gordura, proteína ou energia, em função do logaritmo do PCVZ, para os quatro níveis de concentrado na dieta, indicou não haver diferença entre os tratamentos. Portanto, pode-se recomendar o uso da equação conjunta, que é comum 
aos quatro níveis de inclusão de concentrado e aos dois níveis de proteína nas rações.

De acordo com as equações obtidas para os tratamentos em conjunto, observaram-se aumentos nos conteúdos corporais de gordura (de 24,40 para $75,35 \mathrm{~kg}$ ), proteína (de 35,63 para $75,33 \mathrm{~kg}$ ) e energia (de 429,18 para $1138,45 \mathrm{Mcal}$ ), com aumento do PV dos animais de 200 para $450 \mathrm{~kg}$. Os conteúdos de gordura, em g/kg de PCVZ, aumentaram de 135,9 para 186,6 , e de energia, em Mcal/kg de PCVZ, de 2,39 para 2,81, enquanto os de proteína, em $\mathrm{g} / \mathrm{kg}$ de PCVZ, diminuíram de 198,5 para 186,5 , com o aumento do PV de 200 para $450 \mathrm{~kg}$. Estes resultados estão de acordo com os relatos de Fontes (1995),

Tabela 3 - Parâmetros das equações de regressão do logaritmo dos conteúdos de gordura $(\mathrm{kg})$, proteína (kg) e energia (Mcal) no corpo vazio, em função do logaritmo do peso do corpo vazio $(\mathrm{kg})$ de bovinos Nelore, para os diferentes níveis de concentrado (NC) na dieta, em conjunto, e coeficientes de determinação $\left(r^{2}\right)$

Table 3 - Parameters of logarithm regression equations of contents of fat $(\mathrm{kg})$, protein $(\mathrm{kg})$ and energy (Mcal) in the empty body, on the empty body weight $(\mathrm{kg})$ logarithm of Nellore bulls, for the different concentrate levels in the diet and overall, and coefficients of determination $\left(r^{2}\right)$

\begin{tabular}{|c|c|c|c|}
\hline \multirow[t]{2}{*}{$\mathrm{NC}(\%)$} & \multicolumn{3}{|c|}{$\begin{array}{l}\text { Parâmetro } \\
\text { Parameter }\end{array}$} \\
\hline & $\begin{array}{l}\text { Intercepto (a) } \\
\text { Intercept (a) }\end{array}$ & $\begin{array}{c}\text { Coeficiente (b) } \\
\text { Coefficient (b) }\end{array}$ & $\mathrm{r}^{2}$ \\
\hline & & $\begin{array}{c}\text { Gordura }(\mathrm{kg}) \\
\text { Fat }(\mathrm{kg})\end{array}$ & \\
\hline 20 & $-1,5494$ & 1,2953 & 0,74 \\
\hline 40 & $-1,7056$ & 1,3750 & 0,75 \\
\hline 60 & $-1,8541$ & 1,4446 & 0,86 \\
\hline 80 & $-1,7684$ & 1,4023 & 0,83 \\
\hline \multirow{2}{*}{$\begin{array}{l}\text { Conjunto } \\
\text { Overall }\end{array}$} & $-1,7474$ & 1,3907 & 0,80 \\
\hline & & $\begin{array}{l}\text { Proteína }(\mathrm{kg}) \\
\text { Protein }(\mathrm{kg})\end{array}$ & \\
\hline 20 & $-0,5227$ & 0,9194 & 0,98 \\
\hline 40 & $-0,6345$ & 0,9641 & 0,91 \\
\hline 60 & $-0,4093$ & 0,8730 & 0,98 \\
\hline 80 & $-0,5229$ & 0,9251 & 0,94 \\
\hline \multirow{2}{*}{$\begin{array}{l}\text { Conjunto } \\
\text { Overall }\end{array}$} & $-0,5291$ & 0,9232 & 0,94 \\
\hline & & $\begin{array}{c}\text { Energia (Mcal) } \\
\text { Energy (Mcal) }\end{array}$ & \\
\hline 20 & $-0,0514$ & 1,1406 & 0,87 \\
\hline 40 & $-0,0952$ & 1,2097 & 0,89 \\
\hline 60 & $-0,1030$ & 1,2182 & 0,92 \\
\hline 80 & $-0,0909$ & 1,2114 & 0,92 \\
\hline $\begin{array}{c}\text { Conjunto } \\
\text { Overall }\end{array}$ & $-0,0790$ & 1,2030 & 0,90 \\
\hline
\end{tabular}

R. Bras. Zootec., v.31, n.1, p.503-513, 2002 (suplemento)
Paulino et al. (1999b), Ferreira et al. (1999) e Véras (2000).

As exigências líquidas de proteína, gordura e energia, por kg de ganho de PCVZ, são apresentadas na Tabela 4. Para a conversão das exigências de ganho de PCVZ em exigências de ganho de PV, deve-se multiplicar as exigências de ganho de PCVZ pelo fator 0,96 , que expressa a relação GPCVZ/ GPV, obtido neste trabalho.

Observa-se, na Tabela 4, que os conteúdos de gordura e energia no ganho de PCVZ aumentaram com a elevação do PV ou do PCVZ. Porém, os valores obtidos, para a variação de PV estudada, foram menores que os relatados por Fontes (1995), com animais Nelore, e por Paulino et al. (1999b), com animais de quatro raças zebuínas, porém próximos aos valores de Véras (2000), com animais Nelore. Todos os dados citados são relativos a animais nãocastrados, à semelhança deste experimento. Vale salientar que o peso de abate dos animais, nos experimentos citados, variou até $500 \mathrm{~kg}$ de $\mathrm{PV}$; maiores que o peso de abate $(450 \mathrm{~kg})$ utilizados neste trabalho e no de Véras (2000). Este fato justifica a obtenção de maiores depósitos de gordura e maiores requisitos energéticos pelos animais dos referidos experimentos, visto que, à medida que o peso corporal se eleva, a concentração de gordura aumenta (Berg \& Butterfield, 1976), com concomitante acréscimo nas exigências energéticas, já que o valor energético do ganho aumentou com a elevação do peso dos animais.

Os requisitos líquidos protéicos decresceram, à medida que o PV dos animais se elevou, devido ao aumento da concentração de gordura em detrimento à de proteína, caracterizando menor ganho de proteína porkg de ganho de PCVZ. Segundo Grant \& Helferich (1991), isto se deve à desaceleração do crescimento muscular e ao desenvolvimento mais rápido do tecido adiposo, com a elevação do peso do animal.

Tomando por base um animal de $200 \mathrm{~kg}$ e um de $400 \mathrm{~kg}$ de PV, representando a recria e a engorda, respectivamente, os valores de exigências líquidas de proteína, encontrados nesta pesquisa, foram 7,1 e $15,8 \%$ maiores do que os obtidos por Fontes (1995) e 23,2 e 9,8\% maiores que os valores obtidos por Paulino et al. (1999b) e Véras (2000), respectivamente, para animais de $400 \mathrm{~kg}$ de $\mathrm{PV}$.

Utilizando-se os dados do presente trabalho, foi obtida a seguinte equação para estimativa da proteína retida (PR - g/dia), em função do ganho de peso vivo em jejum (GPVJ), em kg/dia, e da ER (Mcal/dia): 
Tabela 4 - Exigências líquidas de proteína (g) e energia (Mcal), por kg de GPCVZ, e conteúdo de gordura no ganho de peso do corpo vazio ( $\mathrm{g} / \mathrm{kg}$ GPCVZ) de bovinos Nelore, em função do peso vivo (PV)

Table 4 - Net requirements of protein (g) and energy (Mcal), per kg EBW, and fat content in the empty body weight (g/kg EBW) of Nellore bulls, in function of live weight (LW)

$\mathrm{PV}(\mathrm{kg}) \quad$ Exigência

$L W(\mathrm{~kg}) \quad$ Requirement

Proteína

(g/kg GPCVZ)

Protein $(\mathrm{g} / \mathrm{kg} \mathrm{EBW})$
Energia

(Mcal/kg GPCVZ)

Energy (Mcal/kg EBW)

\begin{tabular}{llll}
\hline 200 & 183,22 & 2,88 & 189,07 \\
250 & 180,10 & 3,01 & 206,30 \\
300 & 177,60 & 3,12 & 221,53 \\
350 & 175,51 & 3,22 & 235,28 \\
400 & 173,72 & 3,31 & 247,88 \\
450 & 172,15 & 3,39 & 259,56 \\
\hline
\end{tabular}

$\mathrm{PCVZ}=\mathrm{PV}{ }^{*} 0,8975$

$\mathrm{PR}=-39,0169+200,638 \mathrm{GPVJ}+0,4166 \mathrm{ER} . \mathrm{O} \mathrm{NRC}$ (1996) e Véras (2000) preconizam a equação $\mathrm{PR}=$ GPVJ $(268-(29,4(\mathrm{ER} / \mathrm{GPVJ}))) \mathrm{e}$ $\mathrm{PR}=0,416321+215,345 \mathrm{GPVJ}-14,1352 \mathrm{ER}$, respectivamente, para estimativa dos requisitos líquidos de proteína para ganho (PR). Utilizando a estimativa da ER (3,27 Mcal/dia) para um novilho pesando $400 \mathrm{~kg}$ de PV e com ganho diário de peso vivo de $1 \mathrm{~kg}$, de acordo com a equação de energia retida em função do PCVZ e do ganho de PCVZ (ER = 0,0413 * $\mathrm{PCVZ}^{0,75}$ * GDPCVZ ${ }^{0,978}$ ), descrita posteriormente neste experimento, na equação que estima a $\mathrm{PR}$, deste experimento, obteve-se retenção líquida diária de proteína de $162,98 \mathrm{~g}$. Substituindo estes mesmos dados nas equações do NRC (1996) e de Véras (2000), obteve-se retenção líquida diária de proteína de 171,86 e 169,54 g, respectivamente, valores que foram 5,4 e 4,0\% maiores aos encontrados estimados neste experimento.

$\mathrm{Na}$ Tabela 5, são apresentadas as exigências de PM, calculadas conforme metodologia proposta pelo NRC (1996), utilizando-se os valores referentes às exigências líquidas de proteína para ganho de peso, relativos aos dados em conjunto. Como pode ser observado, os requisitos de PMm aumentaram com a elevação do PV, o que era esperado, já que as exigências protéicas para mantença são função do PV. Utilizou-se a recomendação de Ainslie et al. (1993) para eficiência de utilização da PM para ganho de 49,2\% para animais com PCVZ acima de $300 \mathrm{~kg}$ e, para animais com menos de $300 \mathrm{~kg}$ de PCVZ, a equação: Eficiência $=(83,4-(0,114 \mathrm{x}$ PCVZ)). Como os valores de exigências líquidas de proteína deste experimento foram próximos aos obtidos por Véras (2000), trabalhando com animais Nelore não-castrados, os requisitos de PM são semelhantes. Para um animal de $400 \mathrm{~kg}$ de PV, ganhando $1 \mathrm{~kg}$ de PV, a exigência de PM, segundo dados deste experimento, é de $665 \mathrm{~g}$, 8\% superiores aos recomendados pelo NRC (1996) para animais taurinos castrados apresentando este mesmo peso e a mesma taxa de ganho.

A partir dos requisitos de PM, apresentados na Tabela 5, e utilizando-se o protocolo recomendado pelo NRC (1996) para conversão dos requisitos totais de PM em exigências de proteína bruta (PB), foram calculados os requisitos diários totais de $\mathrm{PB}$ e as exigências de proteína degradada e não-degradada no rúmen (Tabela 6), utilizando-se o consumo médio

Tabela 5 - Exigências de proteína metabolizável para mantença $(P M m)$ e para ganho $(P M g)$ de $1 \mathrm{~kg}$ de $P C V Z$ (g/kg GPCVZ) de bovinos Nelore, em função do peso vivo (PV)

Table 5 - Requirements of metabolizable protein for maintenance $(\mathrm{MPm})$ and for gain $(\mathrm{MPg})$ of $1 \mathrm{~kg} E B W(\mathrm{~g} / \mathrm{kg} E B W)$ of Nellore bulls, in function of live weight ( $L W)$

\begin{tabular}{ccc}
\hline $\mathrm{PV}(\mathrm{kg})$ & $\mathrm{PMm}^{1}$ & $\mathrm{PMg}^{2}$ \\
$L W$ & $M P m$ & $M P g$ \\
\hline 200 & 202,10 & 291,11 \\
250 & 238,91 & 311,48 \\
300 & 273,92 & 336,96 \\
350 & 307,49 & 356,72 \\
400 & 339,88 & 353,08 \\
450 & 371,27 & 349,90 \\
\hline
\end{tabular}

$\mathrm{PCVZ}=\mathrm{PV} * 0,8975$.

$13,8 \mathrm{~g} / \mathrm{kg}^{0,75}$.

2 Exigência líquidas $/ 0,492$ para PCVZ $>300 \mathrm{~kg}$ (Net requirements/0.492 for $E B W>300 \mathrm{~kg}$ ).

Exigência líquidas/(83,4 - $(0,114 \times \mathrm{PCVZ}))$ para $\mathrm{PCVZ} \leq 300 \mathrm{~kg}$ (Net requirements $/(83.4-(0.114 \times E B W))$ for $E B W \leq 300 \mathrm{~kg})$. 
de nutrientes digestíveis totais (NDT) obtido por Silva (2001). A PMg (kg PCVZ) foi corrigida para ganho de PV pela multiplicação do fator $(0,96)$ encontrado neste experimento. À medida que se elevou o PV do animal, maior pode ser a participação da proteína degradável para o suprimento das exigências totais de $\mathrm{PB}$, indicando que para animais na fase de engorda maiores níveis de nitrogênio não-protéico podem ser utilizados na dieta.

A relação do conteúdo de energia do ganho de peso sobre uma grande variação de consumos de energia metabolizável foi descrita, sob a forma de equação, por Garrett (1980). A equação desenvolvida com novilhos de raças britânicas descreve a relação entre a energia retida (ER) e o ganho diário de peso de corpo vazio (GDPCVZ) para determinado peso de corpo vazio (PCVZ) e é a equação adotada pelo NRC (1996):

$$
\mathrm{ER}=0,0635 \times \mathrm{PCVZ}^{0,75} \times \mathrm{GDPCVZ}^{1,097}
$$

A equação de regressão obtida para descrever a relação entre a retenção diária de energia (ER), em Mcal/dia, e o ganho diário de PCVZ (GDPCVZ), em $\mathrm{kg} /$ dia, a determinado PCVZ, neste experimento foi: $\mathrm{ER}=0,0413 * \mathrm{PCVZ}^{0,75} * \mathrm{GDPCVZ}^{0,978}\left(\mathrm{r}^{2}=0,49\right)$.

A partir desta equação, a ER de um animal com GDPCVZ igual a $1 \mathrm{~kg}$ e PV de $400 \mathrm{~kg}$, é de 3,27 Mcal/ dia. Utilizando este mesmo exemplo e a equação descrita por Véras (2000) $\left(\mathrm{ER}=0,045 * \mathrm{PCVZ}^{0,75} *\right.$ GDPCVZ $\left.{ }^{1,1113}, \mathrm{r}^{2}=0,80\right)$, que trabalhou com Nelores não-castrados, a ER seria de 3,69 Mcal/dia. Fazendo-se a correção da equação do NRC (1996) que descreve uma ER para animais castrados, ou seja, diminuindo

Tabela 6 - Exigências de proteína degradada no rúmen (PDR), proteína não-degradável no rúmen(PNDR) e proteína bruta (PB), em g/dia, de bovinos Nelore, em função do peso vivo (PV), para mantença e ganho de $1 \mathrm{~kg}$ de PV, e consumos médios de NDT (kg/dia)

Table 6 - Requirements of rumen degradable protein (RDP), rumen undegradable protein (RUP) and crude protein $(C P)$, in g/day, of Nellore bulls, in function of live weight $(L W)$, for maintenance and gain of $1 \mathrm{~kg} L W$, and average TDN intakes ( $\mathrm{kg} /$ day)

\begin{tabular}{ccccc}
\hline PV $(\mathrm{kg})$ & PDR & $\begin{array}{c}\text { PNDR } \\
\text { RUP }\end{array}$ & \multicolumn{1}{c}{ PB } & NDT (kg/dia) \\
CW $(\mathrm{kg})$ & $D P R$ & \multicolumn{1}{c}{ TDN (kg/day) } \\
\hline 200 & 432,16 & 256,22 & 688,38 & 3,32 \\
250 & 540,21 & 240,26 & 780,47 & 4,16 \\
300 & 648,25 & 228,16 & 876,41 & 4,99 \\
350 & 756,29 & 207,40 & 963,69 & 5,82 \\
400 & 864,33 & 157,09 & 1021,42 & 6,65 \\
450 & 972,37 & 106,07 & 1078,44 & 7,48 \\
\hline
\end{tabular}

$P C V Z=P V * 0,8975$.

R. Bras. Zootec., v.31, n.1, p.503-513, 2002 (suplemento)
$18 \%$, pois animais castrados têm exigências energéticas $18 \%$ maiores que os não-castrados, ER de um novilho não-castrado de porte médio seria igual a 4,11 Mcal/dia, 25,69\% maior que as exigências obtidas neste experimento.

O fato de a ER obtida com os dados do presente trabalho ser menor que a encontrada pela equação proposta pelo NRC $(1984,1996)$ pode, em parte, ser explicado pelas menores quantidade de gordura entremeada (marmoreio) e gordura total observadas em zebuínos, em relação à maioria dos taurinos.

Pela regressão do logaritmo da produção de calor (PC), em função do consumo de energia metabolizável (CEM), em kcal/PCVZ ${ }^{0,75} /$ dia, foi obtida a equação $\log \mathrm{PC}=1,923+0,0015 \mathrm{CEM}, \mathrm{r}^{2}=0,80$, cujo antilog do intercepto indicou o valor de $83,70 \mathrm{kcal} / \mathrm{PCVZ}^{0,75} /$ dia como exigência de energia líquida de mantença (ELm) dos animais. A partir desta equação, obteve-se o consumo de EM no equilíbrio, ou seja, o ponto no qual a PC foi igual ao CEM, de $131,92 \mathrm{kcal} / \mathrm{PCVZ}^{0,75} / \mathrm{dia}$.

$\mathrm{O}$ valor de energia líquida para mantença $(83,70$ $\left.\mathrm{kcal} / \mathrm{PCVZ}^{0,75} / \mathrm{dia}\right)$, obtida neste experimento, foi maior que o relatado por Paulino et al. (1999a), que obtiveram $60,38 \mathrm{kcal} / \mathrm{kg}^{0,75} /$ dia como exigência de ELm para zebuínos, porém foi bastante próximo aos obtidos por Véras (2000), de 82,79 kcal/PCVZ ${ }^{0,75 /}$ dia, para Nelore não-castrados e, possivelmente, menor ao obtido por Ferrell \& Jenkins (1998), de 82,8 $\mathrm{kcal} / \mathrm{kg}^{0,75} /$ dia, para animais Brahman, devido a unidade expressa que deve ser sempre considerada. Boin (1995) encontrou Elm variando de 69,8 a $79,8 \mathrm{kcal} / \mathrm{kg} \mathrm{PCVZ}{ }^{0,75}$.

Segundo o NRC (1996), animais não-castrados têm requisitos de ELm 15\% maiores que machos castrados e novilhas ( $\left.77 \mathrm{kcal} / \mathrm{kg}^{0,75} / \mathrm{dia}\right)$, segundo Lofgreen \& Garrett (1968), zebuínos são 10\% menos exigentes que taurinos. Assim, a exigência de ELm dos animais do presente experimento, segundo proposição do NRC (1996), seria de 79,70 kcal $/ \mathrm{kg}^{0,75} /$ dia. Calculando-se a ELm em função do PV, para os dados deste experimento, obteve-se um valor de $\mathrm{ELm}=77,2 \mathrm{kcal} / \mathrm{kg}^{0,75} / \mathrm{dia}$.

Para os dados do presente trabalho, as exigências líquidas diárias de energia para mantença, para animais com peso vivo de 200, 250,300, 350, 400 e $450 \mathrm{~kg}$, estão apresentadas na Tabela 7. Estes resultados são maiores que os relatados por Paulino et al. (1999a), com zebuínos, de 4,35; 4,89; 5,40; e 5,90 Mcal/dia, respectivamente, para 300,350, 400 e $450 \mathrm{~kg}$ PV, e bastante semelhantes aos encontrados por Véras (2000). 
Tabela 7 - Exigência líquida diária de energia para mantença (Elm) de bovinos Nelore, em função do peso vivo (PV)

Table 7 - Daily net requirement of energy for maintenance(NEm) of Nellore bulls, in function of live weight (LW)

\begin{tabular}{cc}
\hline PV $(\mathrm{kg})$ & ELm(Mcal/dia) \\
$L W(k g)$ & NEm (Mcal/day) \\
\hline 200 & 4,10 \\
250 & 4,85 \\
300 & 5,56 \\
350 & 6,25 \\
400 & 6,90 \\
450 & 7,54 \\
\hline
\end{tabular}

$P C V Z=P V * 0,8975$.

\section{Conclusões}

As exigências de energia líquida para ganho de peso de zebuínos não-castrados podem ser obtidas pela equação: $E R=0,0413 \times \mathrm{PCVZ}^{0,75} \mathrm{x}$ GDPCVZ ${ }^{0,978}$.

$\mathrm{O}$ requisito energético para mantença foi de $83,70 \mathrm{kcal} / \mathrm{PCVZ}^{0,75}$, para animais não-castrados pertencentes à raça Nelore.

A exigência líquida de proteína para animais Nelore pode ser obtida pela equação: $P R=-39,0169$ $+200,638 \mathrm{GPVJ}+0,4166 \mathrm{ER}$.

\section{Literatura Citada}

AGRICULTURAL AND FOOD RESEARCH COUNCIL AFRC. Energy and protein requirements of ruminants. Wallingford: Commonwealth Agricultural Bureaux International, 1993. 159p.

AGRICULTURAL RESEARCH COUNCIL - ARC. The nutrient requirements of ruminants livestock. London: Commonwealth Agricultural Bureaux, 1980.351p.

AINSLIE, S.J.; FOX, D.G.; PERRY, T.C. et al. Predicting amino acid adequacy of diets fed to Holstein steers. Journal of Animal Science, v.71, p.1312-1319, 1993.

BALDWIN, R.L.; SMITH, N.E.; TAYLOR, J. et al. Manipulating metabolic parameters to improve growth rate and milk secretion. Journal Animal Science, v.51, n.6, p.1416-1428.

BERG. R.T., BUTTERFIELD, R.M. New concepts of cattle growth. New York: Sydney University, 1976. 240p.

BOIN, C. Alguns dados sobre exigências de energia e de proteína de zebuínos. In: PEREIRA, J.C. (Ed.) SIMPÓSIO INTERNACIONAL SOBRE EXIGÊNCIAS NUTRICIONAIS DE RUMINANTES, 1995, Viçosa. Anais... Viçosa, MG: Universidade Federal de Viçosa, 1995. p.457-466.

FERREIRA, M.A.; VALADARES FILHO, S.C.; COELHO DA SILVA, J.F. et al. Composição corporal e exigências líquidas de proteína e energia para ganho de peso de bovinos F1 Simental x Nelore. Revista Brasileira de Zootecnia, v.28, n.2, p.352-360, 1999.

R. Bras. Zootec., v.31, n.1, p.503-513, 2002 (suplemento)
FERRELL, C.L.; JENKINS, T.G. Body composition and energy utilization by steers of diverse genotypes fed a highconcentrate diet during the finishing period: II. Angus, Boran, Brahman, Hereford, and Tuli sires. Journal Animal Science, v.76, p.647-657, 1998.

FONTES, C.A.A. Composição corporal, exigências líquidas de nutrientes para ganho de peso e desempenho produtivo de animais zebuínos e mestiços europeu-zebu. Resultados experimentais. In: PEREIRA, J.C. (Ed.) SIMPÓSIO INTERNACIONAL SOBRE EXIGÊNCIAS NUTRICIONAIS DE RUMINANTES, 1995, Viçosa, MG. Anais... Viçosa, MG: JARD, 1995. p.419-455.

FOX, D.G.; SNIFFEN, C.J.; O'CONNOR, J.D. et al. A net carbohydrate and protein system for evaluating cattle diets: III. Cattle requirements and diet adequacy. Journal Animal Science, v.70, n.11, p.3578-3596, 1992.

FREITAS, J.A. Composição corporal e exigência de energia e proteína de bovinos (zebuínos e mestiços) e bubalinos não castrados, em confinamento. Viçosa: Universidade Federal de Viçosa, 1995. 132p. Dissertação (Mestrado em Zootecnia) - Universidade Federal de Viçosa, 1995.

GARRETT, W.N. Factors influencing energetic efficiency of beef production. Journal of Animal Science, v.51, n.6, p.1434-1440, 1980.

GEAY, Y. Energy and protein utilization in growing cattle. Journal of Animal Science, v.58, n.3, p.766-778, 1984.

GONÇALVES, L.C. Digestibilidade, composição corporal, exigências nutricionais e características das carcaças de zebuínos, taurinos e bubalinos. Viçosa, MG: Universidade Federal de Viçosa, 1988. 238p. Tese (Doutorado em Zootecnia) - Universidade Federal de Viçosa, 1988.

GRANT, A. L.; HELFERICH, W.G. An overview of growth. In: PEARSON, A.M. DUTSON, T.R. (Eds.). Growth regulation in farm animals. London: Elsevier Applied Science. p.1-15, 1991.

HANSKINS, O.G.; HOWE, P.E. Estimation of the composition of beef carcasses and cuts. s.e. USDA (Thecnical BulletinUSDA, 926), 1946.

INSTITUT NATIONAL DE LA RECHERCHE AGRONOMIQUE - INRA. 1988. Alimentation des bovines, ovins, et caprins. Paris: 19888.

ÍTAVO, L.C.V. Consumo, digestibilidade e eficiência microbiana de novilhos alimentados com 20, 40, 60 e $80 \%$ de concentrado. Viçosa, MG: Universidade Federal de Viçosa, 2001. Tese (Doutorado em Zootecnia) - Universidade Federal de Viçosa, 2001.

JORGE, A.M. Ganho de peso, conversão alimentar e características de carcaça de bovinos e bubalinos. Viçosa, MG: Universidade Federal de Viçosa, 1993. 110p. Dissertação (Mestrado em Zootecnia) - Universidade Federal de Viçosa, 1993.

LANA, R.P. Composição corporal e exigênciaS de energia, proteína e macroelementos minerais (Ca, P, Mg, Na e K) de novilhos de 5 grupos raciais, em confinamento. Viçosa, MG: Universidade Federal de Viçosa, 1991. 134p. Dissertação (Mestrado em Zootecnia) - Universidade Federal de Viçosa, 1991.

LOFGREEN, G.P.; GARRETT, W.N.A. System for expressing net energy requeriments and feed values for growing and finishing beef cattle. Journal of Animal Science, v.27, n.3, p.793-806, 1968. 
NATIONAL RESEARCH COUNCIL - NRC. Nutrient requirement of beef cattle. 6.ed. Washington, D.C.: 1984. 90p.

NATIONAL RESEARCH COUNCIL - NRC. Nutrient requirement of beef cattle. 7.ed. Washington, D.C.: 1996. 242p.

PAULINO, M.F.; FONTES, C.A.A.; JORGE, A.M. et al. Exigências de energia para mantença de bovinos zebuínos nãocastrados em confinamento. Revista Brasileira de Zootecnia, v.28, n.3, p.621-626. 1999a.

PAULINO, M.F.; FONTES, C.A.A.; JORGE, A.M. et al. Composição corporal e exigências de energia e proteína para ganho de peso de bovinos de quatro raças zebuínas. Revista Brasileira de Zootecnia, v.28, n.3, p.627-633, 1999b.

PERON, A.J.; FONTES, C.A.A.; GALVÃO, J.G. et al. Tamanho de órgãos internos e distribuição da gordura corporal, em novilhos de cinco grupos genéticos, submetidos a alimentação restrita e ad libitum. Revista da Sociedade Brasileira de Zootecnia, v.22, n.2, p.813-819, 1993.

REGAZZI, J.A. Teste para verificar a identidade de modelos de regressão. Pesquisa Agropecuária Brasileira, v.31, n.1, p.1-17, 1993, 1996.

ROBELIN, J.; GEAY, Y. Body composition of cattle as affected by physiological status, breed, sex and diet. Herbivore nutrition in the subtropical and tropics. p.525-547, 1984.

SALVADOR, M. Exigências de energia e proteína para engorda de novilhos azebuados. Viçosa, MG: Universidade Federal de Viçosa, 1980. 70p. Dissertação (Mestrado em Zootecnia) - Universidade Federal de Viçosa, 1980.

SILVA, D.J. Análise de alimentos (métodos químicos e biológicos). Viçosa, MG: Universidade Federal de Viçosa, 1990. 165p.

SILVA, F.F. Desempenho, características de carcaça, composição corporal e exigências nutricionais (de energia, proteína, aminoácidos e macrominerais) de novilhos Nelore, nas fases de recria e engorda, recebendo diferentes níveis de concentrado e proteína. Viçosa, MG: Universidade Federal de Viçosa, 2001. 211p. Tese (Doutorado em Zootecnia) - Universidade Federal de Viçosa, 2001.
SILVA, J.F.C.; LEÃO, M.I. Fundamentos de nutrição de ruminantes. Piracicaba: Livroceres, 1979. 380p.

SMUTS, D. The relation between the basal metabolism and the endogenous nitrogen metabolism, with particular reference to the maintenance requirement of protein. Journal of Nutrition, v.9, p.403-433, 1935.

SOLIS, J.C.; BYERS, F.M.; SCHELLING, G.T. et al. Maintenance requirements and energetic efficiency of cows of different breed types. Journal of Animal Science, v.66, n.3, p.764773, 1988.

THOMPSON, W.R.; MEISKE, J.C.; GOODRICH, R.D. et al. Influence of body composition on energy requirement of beef cows during winter. Journal of Animal Science, v.56, n.5, p.1241-1252, 1983.

UNIVERSIDADE FEDERAL DE VIÇOSA - UFV. SAEG Sistema de análises estatísticas e genética. Viçosa, $\mathrm{MG}$ : 1995.

VÉRAS, A.S.C. Consumo, digestibilidade, composição corporal e exigências nutricionais de bovinos Nelore alimentados com rações contendo diferentes níveis de concentrado. Viçosa, MG: Universidade Federal de Viçosa, 2000. 192p. Tese (Doutorado em Zootecnia) - Universidade Federal de Viçosa, 2000.

WILKERSON, V.A.; KLOPFENSTEIN, T.J.; BRITTON, R.A. et al. Metabolizable protein and amino acid requirements of growing beef cattle. Journal of Animal Science, v.71, p.2777-2784, 1993.
Recebido em: 29/04/01

Aceito em: 29/11/01 